\title{
Ishod duboke moždane stimulacije kod Parkinsonove bolesti u pacijentice starije životne dobi - prikaz slučaja
}

\section{Outcome of deep brain stimulation in Parkinson's disease in an elderly patient - case report}

\author{
Mario Hero ${ }^{1^{*}}$, Vladimira Vuletic ${ }^{1,2}$
}

${ }^{1}$ Sveučilište u Rijeci, Medicinski fakultet, Rijeka, Hrvatska

${ }^{2}$ Klinika za neurologiju KBC-a Rijeka, Rijeka, Hrvatska

\section{"Dopisni autor:}

Mario Hero

Sveučilište u Rijeci, Medicinski fakultet

Braće Branchetta 20, 51000 Rijeka

E-mail: mario.hero10@gmail.com
Sažetak. Cilj: Prikazati ishod duboke moždane stimulacije (engl. Deep brain stimulation, DBS), tijekom vremenskog razdoblja od 2,5 godine, u sedamdeset osmogodišnje pacijentice koja boluje od Parkinsonove bolesti (PB) rezistentne na lijekove. Prikaz slučaja: Prikazujemo slučaj pacijentice u dobi od 74 godine koja je bila zainteresirana za DBS zbog PB-a rezistentnog na lijekove. Bolest se manifestirala u obliku tremora lijeve ruke i noge te je uvelike narušavala njezinu kvalitetu života. U dobi od 75 godina ugrađen joj je DBS u suptalamičke jezgre (engl. subthalamic nucleus, STN) obostrano. Na prvom poslijeoperacijskom kontrolnom pregledu ustanovljeno je da nakon stimulacije gotovo nije bilo tremora $\mathrm{i}$ govor je bio uredan. Stimulacije elektroda bile su postavljene desno (D 0- 2.1 V $90 \mu \mathrm{s} 130 \mathrm{~Hz}$ ) i lijevo (L 8- 0.8 V 90 us $130 \mathrm{~Hz}$ ). Tijekom 2,5 godine pacijentica je redovito kontrolirana i stimulacija elektroda bila je izmijenjena u dva navrata. Na zadnjem kontrolnom pregledu navela je da je nesmetano obavljala svakodnevne aktivnosti te se čak i bavila pletenjem, što prije nije mogla. Također, pacijentica je bila dobro kognitivno očuvana. Razina stimulacije elektroda iznosila je desno D 0- 2.4 V 90 us 130 Hz i lijevo - L 8- 1.0 V 90 us 130 Hz. Zaključak: Kod pažljivo odabranih kandidata, koji duže godina boluju od PB-a rezistentnog na medikamentoznu terapiju, dob iznad 70 godina ne bi trebala predstavljati kontraindikaciju za DBS STN. Prikazani slučaj pokazuje da DBS STN može biti koristan u smanjenju simptoma i time značajno poboljšati kvalitetu života takvih pacijenata.

Ključne riječi: duboka moždana stimulacija; Parkinsonova bolest; suptalamička jezgra

Abstract. Aim: To present the outcome of deep brain stimulation (DBS) through a time period of 2.5 years, in a seventy-eight-year-old female suffering from drug-resistant Parkinson's disease (PD). Case report: We present the case of a 74-year-old patient who was interested in DBS due to drug-resistant PD. The disease manifested itself in the form of tremor of the left arm and leg and greatly impaired her quality of life. At the age of 75 , she was embedded with DBS in the subthalamic nuclei (STN) bilaterally. At the first postoperative check-up, it was found that there was almost no tremor after stimulation and the speech was orderly. Electrode stimulations were placed on the right (D 0-2.1 V $90 \mu \mathrm{s} 130 \mathrm{~Hz}$ ) and on the left ( $\mathrm{L}$ 8$0.8 \vee 90 \mu \mathrm{s} 130 \mathrm{~Hz}$ ). Over a period of 2.5 years, the patient was regularly monitored and electrode stimulation was changed twice. At the last check-up, she stated that she performed her daily activities without hindrance and in her free time she was even knitting, what she couldn't do before. Also, the patient was well cognitively preserved. The level of electrode stimulation was right (D 0-2.4 V $90 \mu \mathrm{s} 130 \mathrm{~Hz}$ ) and left (L 8- 1.0 V $90 \mu \mathrm{s} 130 \mathrm{~Hz}$ ). Conclusion: In carefully selected candidates, who have been suffering from drug-resistant PD for many years, age over 70 years should not be a contraindication for DBS STN. The presented case shows that DBS STN can be useful in reducing symptoms and thus significantly improve the quality of life in such patients.

Key words: deep brain stimulation; Parkinson's disease; subthalamic nucleus

http://hrcak.srce.hr/medicina 


\section{UVOD}

Parkinsonova bolest (PB) kronična je progresivna neurodegenerativna bolest karakterizana odlaganjem abnormalnih agregata koji uzrokuju značajan gubitak dopaminergičnih neurona u području pars compacta substantia nigra ${ }^{1}$. Posljedično, raspoložive su manje količine dopamina te dolazi do pojave motoričkih i nemotoričkih simptoma. Rani motorički simptomi uspješno se liječe primjenom L-izomera 3,4-dihidroksifenilalanina (LDOPA), ali u uznapredovaloj bolesti diskinezije motoričke fluktuacije i nemotorički simptomi bitno sužavaju terapijske mogućnosti ${ }^{2}$. DBS je postao metoda izbora za uznapredovale stadije PB-a, a pokazao se učinkovitom i kod određenih vrsta distonija i rezistentnih esencijalnih tremo$\mathrm{ra}^{3}$. Operacija je usmjerena na ventralnu intermedijarnu jezgru (VIM) talamusa ako se radi o tremor-dominantnom obliku PD-a i kod starijih, a na suptalamičku jezgru (STN) i globus pallidus internus (GPi) ako je riječ o akinetičko-rigidnom obliku bolesti ${ }^{3}$. Za postizanje što veće učinkovitosti bitno je pažljivo odabrati pacijente i elektrode precizno postaviti u ispravan položaj, no najvažniji faktor uspješnosti liječenja jest pravilno programirati DBS uređaj. Također, programiranje je i jedini faktor koji je moguće mijenjati nakon implantacije elektroda, stoga postaje i važniji u slučajevima kada su elektrode implantirane na rubu ciljne regije ${ }^{4}$. U starijoj dobi nakon DBS STN postoji opasnost od bržeg kognitivnog propadanja i razvoja neuropsihijatrijskih simptoma, stoga se dob iznad 70 godina smatra kontraindikacijom za DBS STN. U radu je prikazan slučaj pacijentice koja boluje od PB-a kojoj je u 75. godini ugrađen DBS STN te se prati u periodu od 2,5 godine.

\section{PRIKAZ SLUČAJA}

Pacijentica u dobi od 74 godine bila je upućena na Kliniku za neurologiju Kliničkog bolničkog centra u Rijeci zbog tremora lijeve ruke i noge. Sedam godina ranije dijagnosticiran joj je PB i od tada je peroralno primjenjivala levodopu s benzerazidom (375 mg/dan) i ropinirol s produljenim otpuštanjem (4 mg/dan). Kratak period primjenjivala je i amantadin koji joj je ukinut jer ga nije tolerirala. Također, nije tolerirala više doze dopamina, a ni ostale antiparkinsonike. U fizikalnom statusu utvrđeni su hipomimija, hod sitnijim koracima uz reducirane sintetske kretnje lijevo te povišen tonus po ekstrapiramidnom tipu.

Od nemotoričkih simptoma imala je problema sa spavanjem, konstipacijom, umorom, bolovima, anksioznošću. Kognitivne su funkcije bile zadovoljavajuće. Magnetska rezonancija (engl. Magnetic resonance imaging; MRI) iz 2011. godine prikazivala je vaskularne lezije. Navedena terapija nije se pokazala uspješnom u kontroli tremora te joj je podignuta doza levodope s benzerazidom na

Duboka moždana stimulacija suptalamičke jezgre postala je metodom izbora za uznapredovale stadije Parkinsonove bolesti rezistentne na medikamentoznu terapiju. Sigurnost i učinak te metode još nije dovoljno istražen u pacijenata starije životne dobi pa se zbog toga u smjernicama dob iznad 70 godina navodi kao kontraindikacija za tu operaciju.

500 mg/dan. Pacijentica je navela zainteresiranost za DBS te je bila upućena da napravi MR mozga i neuropsihološko testiranje. Za pet mjeseci pacijentica je došla na pregled kada je ustanovljeno da nije postignut željeni učinak na tremor, no zakočenost je bila manja. S obzirom na dob, preporučen joj je DBS VIM desno prije kojeg je bilo potrebno napraviti klasičnu laboratorijsku obradu, ultrazvuk abdomena i rendgen pluća. Nakon ponovnog razmatranja simptoma i kognitivnog stanja, nakon tri mjeseca u dobi od 75 godina ugrađen joj je, unatoč prethodnoj preporuci, DBS STN (engl. subthalamic nucleus, STN) obostrano. Za četiri mjeseca pacijentica je došla na prvi poslijeoperacijski kontrolni pregled. Navela je da je imala smetnje u govoru i manji tremor, ali da se osjećala dobro. Nemotorički simptomi bili su zadovoljavajuće poboljšani, nisu joj više smanjivali kvalitetu života. Nakon stimulacije gotovo da nije bilo tremora i govor je bio uredan. Stimulacije elektroda bile su postavljene desno (D 0- $2.1 \mathrm{~V} 90$ us 130 Hz) i lijevo (L 8- 0.8 V 90 us 130 Hz). Terapija joj je ostala ista. Za šest mjeseci na kontrolnom pregledu navela je da se tremor opet pojavio te da je bila uredno aktivna i manje zakočena. Stimulacije su iznosile desno - D 0- 2,2V 90 us $130 \mathrm{~Hz}$ i lijevo - L 8- 1.0 V 90 us 130 Hz. Na 
sljedećem pregledu za šest mjeseci pacijentica je isticala smetnje ravnoteže, blagi tremor lijeve ruke i smetnje u govoru. U terapiju joj je bio dodan betahistinum za kontrolu ravnoteže te joj je bila preporučena fizikalna terapija kod kuće. Elektrode su bile namještene desno (D 0- $2.4 \mathrm{~V} 90 \mu \mathrm{s}$ $130 \mathrm{~Hz}$ ) i lijevo (L 8- 1.0 V 90 s 130 Hz). Na idući je pregled došla za pet mjeseci te je tvrdila da se osjeća dobro (subjektivna i objektivna procjena). Nije imala tremor niti smetnje govora, ali je bila prisutna blaga bradikinezija. Elektrode su ostale na istoj razini stimulacije, desno -D 0- $2.4 \mathrm{~V} 90 \mu \mathrm{s}$ $130 \mathrm{~Hz}$ i lijevo - L 8- 1.0 V 90 s 130 Hz. Dobila je preporuku za logopedski tretman po Lee-Silvermanovoj metodi. Na zadnjem kontrolnom pregledu za sedam mjeseci navela je da je ponekad imala smetnje s ravnotežom, ali nije imala tremora niti smetnje govora. Nesmetano je obavljala svakodnevne aktivnosti te se u slobodno vrijeme čak i bavila pletenjem, što prije nije mogla. Također, pacijentica je bila dobro kognitivno očuvana. Razina stimulacije elektroda ostala je ista, desno

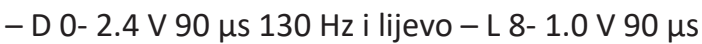
$130 \mathrm{~Hz}$.

\section{RASPRAVA}

Razvoj PB-a rezistentnog na različite lijekove predstavljao je u pacijentice indikaciju za DBS STN. Zbog dobi od 75 godina pacijentica nije bila idealan kandidat za takav operativni zahvat. Naime, uporaba DBS-a u osoba koje su u vrijeme operacije starije od 70 godina zahtijeva posebnu opreznost, posebno STN kao ciljno mjesto. U opisanim slučajevima obično se preporučivao unilateralni VIM kao ciljno mjesto riskirajući da se popravi samo tremor na jednoj strani, a bradikineza i rigor ostanu nepromijenjeni s obzirom na poznati učinak DBS VIM-a ${ }^{5}$. Zbog povećane učestalosti komorbiditeta i poslijeoperacijskih komplikacija te mogućeg izostanka pozitivnih učinaka DBS-a kod te ciljne skupine, dob iznad 70 godina po nekim se autorima smatra kontraindikacijom za ovu operaciju3 ${ }^{3}$. Konkretno, DBS se povezuje s poslijeoperacijskim komplikacijama kao što su infekcija rana, krvarenje, upala pluća, plućna embolija, neurološke posljedice, pa čak i smrt. U starijoj dobi nakon DBS STN-a postoji opasnost od bržeg kognitivnog propadanja i razvoja neu- ropsihijatriskih simptoma. Posljedica je navedenih rizika operacije da mnogi DBS timovi nerado preporučuju starijim pacijentima operaciju za implantaciju DBS-a, a to rezultira manjkavim podatcima o korisnosti takve operacije u starijih od 70 godina ${ }^{6}$.

Po novijim istraživanjima nije dokazana povećana smrtnost starijih od 75 godina kod ove operacije. Stariji pacijenti pokazivali su sličan rizik za razvoj komplikacija kao i mlađi unutar 90 dana od operacije. Prema tome, pacijente s očuvanim kognitivnim sposobnostima koji imaju PB rezistentan na lijekove ili on-off fluktuacije trebalo bi razmatrati kao kandidate za DBS bez obzira na dob stariju od 70 godina ${ }^{7}$.

Drugi važan faktor u razmatranju DBS-a jest sama učinkovitost operacije na simptome u osoba starijih od 70 godina. Treba uzeti u obzir činjenicu da prosječna dob pacijenata kojima se dijagnosticira PB iznosi 60 godina te da bolest prosječno traje 14 godina prije implantacije $D_{B S}-a^{3}$. Iz tog vremenskog okvira proizlazi da su podatci o učinku DBS-a u populaciji starijih od 70 godina izuzetno važni te zbog toga postaju fokus sve većeg broja istraživanja. Već i postoje istraživanja koja pokazuju obećavajuće rezultate ${ }^{6,8}$. Uz ta istraživanja možemo pridružiti i naš slučaj jer se radi o pacijentici koja ima zajedničke kriterije dugogodišnjeg bolovanja od PB-a i implantaciju DBS-a poslije 70. godine života.

DBS ima najbolji učinak na motoričke simptome PB-a kao što su tremor i rigor ${ }^{9}$. Upravo ti simptomi najviše ometaju svakodnevne aktivnosti pacijenata. Pacijenti su nakon ugradnje DBS-a mogli lakše obavljati svakodnevne aktivnosti uz gotovo potpuni izostanak simptoma ${ }^{10,11}$. Slična je situacija i kod naše pacijentice kod koje je tijekom nekoliko mjeseci nakon operacije opaženo smanjenje motoričkih simptoma i prijavljeno uredno obavljanje svakodnevnih aktivnosti. Uz smanjenu pojavu motoričkih simptoma i zadovoljavajuće nemotoričke simptome, također se ponovno počinje baviti hobijima poput pletenja koji iziskuju povećanu motoričku kontrolu.

Uz ublažavanje motoričkih simptoma DBS je pokazao i rezultate u smanjenju levodopaekvivalentne dnevne doze (engl. levodopa equivalent daily dose, LEDD). Naime, kod pacijenata je uočeno da 
je potrebna manja doza LEDD-a nakon ugradnje DBS-a ${ }^{11}$. Kod naše pacijentice to nije moguće usporediti jer je ona na alternativnoj terapiji zbog nepodnošenja dopamina i ostalih antiparkinsonika. Poboljšanje motoričkih simptoma, zadovoljavajući nemotorički simptomi i smanjene potrebe za medikamentoznom terapijom imaju izrazito važan učinak na smanjenje negativnih simptoma koji prate dugoročno uzimanje dopaminergične terapije. Uz to važno je i napomenuti da navedeni kombinirani učinak DBS-a omogućuje ljudima olakšanje od stresa koji prati složene rasporede uzimanja lijekova, a to je naročito korisno kod starije populacije ${ }^{11}$.

Važnost ovog prikaza jest u dugotrajnom praćenju pacijentice nakon ugradnje DBS STN-a. Naime, višegodišnje praćenje pacijenata oboljelih od PB-a kojima je iza 70. godine života ugrađen DBS rijetko je, posebno kao u našem slučaju od dobi 75 do 78 godina. Zbog brojnih komplikacija operacije i prijašnjoj zastupljenosti mišljenja o neučinkovitosti DBS-a, tek se odnedavno ova operacija počela razmatrati kao moguće rješenje PB-a u starijih od 70 godina. Za sada istraživanja pokazuju obećavajuće rezultate, ali još uvijek postoji potreba za dodatnim podatcima, posebno o prediktorima dobrog ishoda i poslijeoperacijskom praćenju kroz prikaze što više slučaja, kako bi se promijenila u smjernicama i dalje prisutna dob od 70 godina kao kontraindikacija za DBS. Unatoč tome što je dob iznad 70 godina kontraindikacija za DBS, naš slučaj pokazuje da pomnim odabirom pacijenata, sigurnom i efikasnom implantacijom elektroda i dobrim poslijeoperacijskim praćenjem, DBS STN može dugoročno uvelike poboljšati kvalitetu života takvih pacijenata pa ga i u toj dobi treba razmatrati.

\section{ZAKLJUČAK}

Gornja dobna granica za ugradnju DBS STN-a još uvijek je predmet mnogih rasprava te se dob iznad 70 godina kod pažljivo odabranih kandidata ne bi trebala smatrati kontraindikacijom. Prikazani slučaj pokazuje da DBS STN može biti koristan u smanjenju simptoma PB-a rezistentnog na medikamentoznu terapiju i time značajno poboljšati kvalitetu života u pacijenata starijih od 70 godina. Specifičnost ovog slučaja jest višegodišnje praće- nje pacijentice nakon ugradnje DBS STN-a od dobi 75 do 78 godina, koje je pokazalo postojano smanjenje tremora, bradikineze, rigora, poboljšanje pokretljivosti i nemotoričkih simptoma, posebno kognitivnih funkcija, obavljanja svakodnevnih aktivnosti i kvalitete života uz mogućnost ponovnog bavljenja hobijima kojima se prije DBS-a nije mogla baviti. Radi dobrog učinka i zadovoljavajuće sigurnosti, DBS STN treba i u dobi iznad 70 godina

Pokazali smo kako se ta metoda pokazala vrlo učinkovitom i zadovoljavajuće sigurnom u pacijentice starije životne dobi te bi zbog toga trebalo DBS STN razmatrati opcijom i u dobi iznad 70 godina kako oboljeli od Parkinsonove bolesti te dobne skupine ne bi bili zakinuti za jednu tako uspješnu i učinkovitu metodu.

razmatrati kako oboljeli od PB-a te dobne skupine ne bi bili zakinuti za jednu tako uspješnu i učinkovitu metodu koja može promijeniti kvalitetu njihova života i života njihove obitelji. Daljnje kontrolirane i veće studije svakako su potrebne da potvrde dobre ishode u toj dobi.

Izjava o sukobu interesa: autori izjavljuju kako ne postoji sukob interesa.

\section{LITERATURA}

1. Rua Rafael AS, Pinto Barbosa JM, Silva Leão Rosas MJ, Lobo Almeida Garrett MC. Parkinson's Disease and development of levodopa induced motor complications: Influence of baseline features and first medical approach. Porto Biomed J 2016;1:136-41.

2. Mitchell KT, Younce JR, Norris SA, Tabbal SD, Dowling JL, Rich KM et al. Bilateral Subthalamic Nucleus Deep Brain Stimulation in Elderly Patients With Parkinson Disease: A Case-Control Study. Operative neurosurgery 2020; Forthcoming.

3. Mathkour M, Garces J, Scullen T, Hanna J, Valle-Giler E, Kahn L et al. Short- and Long-Term Outcomes of Deep Brain Stimulation in Patients 70 Years and Older with Parkinson Disease. World Neurosurg 2017;97:247-52.

4. Koeglsperger T, Palleis C, Hell F, Mehrkens JH, Bötzel K. Deep Brain Stimulation Programming for Movement Disorders: Current Concepts and Evidence-Based Strategies. Front Neurol 2019;10:410.

5. S. J. Groiss, L. Wojtecki, M. Südmeyer, A. Schnitzler. Deep Brain Stimulation in Parkinson's Disease. Ther Adv Neurol Disord 2009;2:20-28.

6. Hanna JA, Scullen T, Kahn L, Mathkour M, Gouveia EE, Garces J et al. Comparison of elderly and young patient populations treated with deep brain stimulation for Parkinson's disease: long-term outcomes with up to 7 years of follow-up. J Neurosurg 2018;131:807-12. 
7. DeLong MR, Huang KT, Gallis J, Lokhnygina Y, Parente B, Hickey $P$ et al. Effect of advancing age on outcomes of deep brain stimulation for Parkinson disease. JAMA Neurol 2014;71:1290-5.

8. Chiou SM. Benefits of subthalamic stimulation for elderly parkinsonian patients aged 70 years or older. Clin Neurol Neurosurg 2016;149:81-6.

9. Diana Dragija, Olivera Mihordin. The Role of Deep Brain Stimulation Procedure on the Quality of Life in Patients with Parkinson's Disease. Croat Nurs J 2018;2:111-17.
10. Derost PP, Ouchchane L, Morand D, Ulla M, Llorca PM, Barget $M$ et al. Is DBS-STN appropriate to treat severe Parkinson disease in an elderly population? Neurology 2007;68:1345-55.

11. Dafsari HS, Reker P, Stalinski L, Silverdale M, Rizos A, Ashkan K et al. Quality of life outcome after subthalamic stimulation in Parkinson's disease depends on age. Mov Disord 2018;33:99-107. 